\title{
THE ROLE OF DANCE AND WHAT IT TEACHES ABOUT THE TRANSCENDENCE IN POSSESSION AND EFFICACY AMONG THE BREKETE GATSI CULT
}

\author{
SenYo OKYERE \\ Choreomundus - International Master in Dance Knowledge, Practice and Heritage \\ Nana Achempong, 107 Kensington Ave, Apt 102 Jersey City, NJ 07304 \\ E-mail: cecil.s.okyere@hotmail.com
}

\begin{abstract}
This research was conducted on the Brekete Gatsi cult in Ghana to investigate the use of the body in action during the dance in the ritual context. Brekete is a possession cult found among the Ewe's of the Volta Region-Ghana. Devotees in this cult worship the deities Kunde and Ablewa on every Friday, Sunday and during ceremonial days. They also propitiate other pantheons who are children of Kunde and Ablewa. During ritual moments they call on these deities, who manifest themselves by embodying trained mediums to enter into an act of communion with the religious community. This state of embodiment is manipulated by rhythms paralleled with ritual sacrifices and dance which the community believes attains efficacy through possession.

Therefore, this article will discuss the role of two dances which are performed during the ritual of the cult. Both dances occur during the same ritual events but may be distinguished by the fact that one of them is accompanied by possession and the other is not. I have therefore labelled them as $W u$ (Dance) and Trowo le ewu $d u$ (deities are dancing). It is through the analysis of these dances that it is possible for the reader to understand the relationship between the mundane world and the supernatural world of the people who perform in this cult. The methodology used has been that of classical anthropological research approach and more particularly of participant observation of events of which I had no prior knowledge due to my Christian urban upbringing. I wish to highlight the exoticism of the experience for a researcher who, despite his own upbringing, tackled a different religious phenomenon irrespective of his social and religious affiliations.

Thus, with my focus on the bodily actions and how they are used to gain access into the celestial world, I identify dance as an instrument and a medium by which the physical evidence of possession comes about. To that effect, and through the phenomenon that religious possession dance is laden with complexities and meaning, this article will hereby develop how the ritual processes and the differences between the movement of "Wu and Trowo le ewu $d u$ " teaches us about the ritual efficacy of possession dance. I argue here that both possession dance and the dance without possession (i) are contra-kinetically constructed, (ii) have movement sequences employing sagittal symmetrical principles, and (iii) although they have limited motifs of the steps and arm gesture, the possession dance has many variations.

Finally, the $W u$ serves as a prelude to Tro di amedzi (deity has embodied or mounted its medium) and Trowo le ewu $d u$, which has the concept of possession among the Brekete Gatsi cult based on the philosophy of repetitive motif characterised by intense energy, rhythmic tempo and musicality (multidimensional, accentuation and phrasing) from the brekete drum.
\end{abstract}

Keywords: dance, ritual, religion, possession 


\section{REFERENCES}

'the subject constitutes himself in an active fashion, by the practices of the self; these practices are nevertheless not something that the individual invents by himself. They are patterns that he finds in his culture and which are proposed, suggested and imposed on him by his culture, his society and his social group'

(Andrée Grau 2012)

'those concerned primarily with salvation from all the ills of this world are soteriological, those which express the solidarity of the group or incorporate individuals within it are social, and those which attempt to cure illness, ensure a successful business enterprise or the passing of an exam may be considered instrumental'

(David Gellner 1999: 142)

'what do we do with people who claim none, in fact are insistent that they are not there at all, and are totally away possessed by a god or spirit? How do we go along ways of being-in-the-world so radically different from our own possibilities? If the people having such experiences can tell us nothing about it, and, given the fact that gods do not generally grant interviews to ethnographers, what kind of access can we have to such worlds? What does it mean to be embodied by a deity, to be-there and not-there at the same time'

(Steven FreIDSON 2009: 9)

'generally denotes the incarnation or possession of an individual by some spiritual being and not by some vague "external forces". According to the culture, the spirit may "possess" or control the individual person in a number of different ways - it may reside in the head, "ride" the individual as a horse, or a spirit might fully incarnate the person, taking full control of his or her body - and the person is "seized" by the divinity or spirit. He or she then becomes a "vessel" or "temple" or the embodiment of the spirit"

(Morris BRYAN 2006: 22)

'considers everyday actions as well as rituals and artistic event as performative and seeks to analyse the "doing" of performance across a range of modalities of artistic cultural expression'

"studying and performing the very "embodiment of a cultural tradition" is the gaining the kinaesthetic understanding of the cosmological and ontological knowledge of the deities'

(Ann DAVID 2009)

'ritual is religious, and religion involves both social experiences in ritualistic activity and a systematic corpus of beliefs which have for their object invisible and intangible beings or powers which a human group recognizes as superior, on which it depends'

(Victor TURNER 1982: 201)

'a collective expression of history and culture through drumming, singing, movements and gestures'

(Sylvanus Kuwor 2013: 19) 
'Union of sound and action is of importance whatever the context, there must be drumming and dancing at the funeral as at the festivals'

(Kwabena Nketia 1963: 174)

'Dance continues to facilitate adaptation to the supernatural environment'

(Judith Lynn HanNaH 1973: 8-9)

'link a social system and its environment, specifically extracting goods and services from the environment for the society'

(Southern Anthropological Society, Columbia, Missouri, February 24-26, 1972)

'the dancing has a pre-defined order and devotees never dance alone; they either dance together in two, three and four. And, depending on the direction; either towards the Bishop, drummers and other devotees where the dancers are heading towards, on reaching that point, they either take a bow or prostrate'

(Senyo OKYere 2014: 16)

'oral sources constitute a privileged means of access to constructing dance histories, especially as the music, in particular drumming and song which accompany the dance usually refer in some way to the meaning, history or context of the dance'

(Georgiana GoRE 2006: 79)

'rather than using the terminology of Western music - compound time or 12/8 time signature - I will designate this temporal structure as ternary-quadruple, i.e., beats hold three equal units, with four beats within one occurrence of the bell phrase. The temporal units within beats are termed fast pulses or time points'

(David Locke 2009)

'contrakinesis as an immediate, successive movement opposition, which means movement pairs where a movement is followed right on the next rhythmical unit by an opposite one. Contrakinesis is primarily a principle of motive creation'

'is a mirrored performance of movement sequence, is a principle of structuring dance and a characteristic feature of folk dance'

(János FÜGEDI 2012)

\section{BACKGROUND OF THE BREKETE GATSI CULT}

The Gatsiawo $^{l}$ call, as one would hear whenever there is a ritual activity among its numerous members, are that of the practitioners of the Brekete ritual. Although the cult members and organizations tend to vary from one Ewe group to the other, all the devotees are worshippers of the divinities Kunde and Ablewa. Ewe is the generic name for all the

${ }^{1}$ Gatsi is the family of the priest who owns the gods. Wo is a suffix to form plural to nouns. 
different sub-groups ${ }^{2}$ that constitute the people known as Ewes. This research was focused on the Gatsi family in 2013 at the head shrine of the priest in Dansoman, a branch shrine in Ashiaman, and Klikor - all suburbs in Accra and Volta Region.

The Gatsi family are the custodians and owners of the pantheons in the Brekete cult but the religious community is made up of worshipers from different groups. Most of the devotees to this cult were born and initiated into the shrine practices and some of the devotees also became part of the shrine through their religious exploration into something efficacious that they can believe in. Andrée Grau duly observed this notion and contends thus.

The subject constitutes himself in an active fashion, by the practices of the self; these practices are nevertheless not something that the individual invents by himself. They are patterns that he finds in his culture and which are proposed, suggested and imposed on him by his culture, his society and his social group. ${ }^{3}$

Individuals who were invited to or witnessed the ritual processes of the cult and believed in its supernatural potency eventually found a salvation in the Brekete shrine. This is because the patterns in the performance of their ritual can be ascribed to have the possibility of combining more than one type of categorization ${ }^{4}$ when the practice of religion is deconstructed into soteriological/salvation, social/communal, and instrumental experiences.

Bishop Anane Gatsi is the head priest of the shrine at Dansoman. 'Bishop' as he is popularly known is the leader of forty-one Brekete shrines out of which he inherited seven from his late father Kwomi Michael Gatsi Fiawoshi. The shrines are referred to as branches and they are located in many towns within the ten Regions of Ghana. Anane Gatsi became a worshiper of Kunde and Ablewa on 04 ${ }^{\text {th }}$ April 1964 because he believed the gods called on him. He was born into a traditional religious family in the Volta Region with his brothers at a time his father Kwomi Michael Gatsi Fiawoshi was the priest of the Brekete pantheons in the 1960s. Presently his son William Gatsi, affectionately known as Kpegdziga ${ }^{5}$ Paa Willie, is currently responsible for all the ritual worship at the Dansoman shrine.

\section{RITUAL AND RELIGION IN PRACTICE IN THE CULT}

There is a vast literature written either singularly on ritual, religion, possession and dance, or the relationships between them have been discussed to a greater extent. This research seeks to contribute to the existing knowledge on the role of dance in possession.

\footnotetext{
${ }^{2}$ These sub-groups can be identified mostly by their names (Kpando, Hohoe, Ave, Peki, Aylo, etc), dance genres, spoken languages, and their geographical location.

32012.

${ }^{4}$ Those concerned primarily with salvation from all the ills of this world are soteriological, those which express the solidarity of the group or incorporate individuals within it are social, and those which attempt to cure illness, ensure a successful business enterprise or the passing of an exam may be considered instrumental. (Gellner 1999: 142)

${ }^{5}$ Title for ritual mediators.
} 
I advance with the notion that ritual can either be religious or not and in this religious context the practitioners commune ritually towards a transcendental end. The conceptualization of the Brekete religious culture includes the knowledge of the universe and more so about the general truth of the divine and the moral state of living. Devotees believe that the universe consists of dynamic forces which influence and manifest themselves through divination and possession. Both the living and non-living and other supernatural beings possess an important force in different degrees. They again believe that as a result of the interrelation of these forces which at times affect human existence in negative ways, it becomes important for mankind to gain the knowledge and use these natural forces in influencing their existence. This doctrine is fundamental in building a relationship with the deities Kunde and Ablewa. The dogmas of the Brekete cult are syncretic ${ }^{6}$ by process, form and function, and through these beliefs the cult's ritual activity is capacitated to function at any secular or sacred social event. Victor and Edith Turner add that, 'ritual is religious, and religion involves both social experiences in ritualistic activity and a systematic corpus of beliefs which have for their object invisible and intangible beings or powers which a human group recognizes as superior, on which it depends'? The act of spirit-possession and dance is not too different in this form, as processes to attain religious efficacy are consciously calculated and manipulated through ritual organization.

\section{PURPORTING TO BE FACTUAL OR BELIEVING IN RELIGION - ROLE OF DANCE}

I will not be in denial that the phenomenon relating to factuality or beliefs in religion and spirit-possession ${ }^{8}$ which is profoundly situated in religious beliefs is complex and as such arouses ambiguities. Steven Freidson an ethnomusicologist and anthropologist in his investigations to gain insight into some of these questions about possession advanced through enquiry that,

What do we do with people who claim none, in fact are insistent that they are not there at all, and are totally away possessed by a god or spirit? How do we go along ways of being-in-the-world so radically different from our own possibilities? If the people having such experiences can tell us nothing about it, and, given the fact that

\footnotetext{
${ }^{6}$ The cult processes are intertwined with Muslim practice of prayer, observance of some Muslim calendric event, chewing of kola nut, the use of the buta, devotees dressing up in thoub and Hijab. In that light, the gods from their origin were Muslim incarnates. However, the title (Bishop) given to the priest is of Christian association, but no matter how these influx and influence occur, their practices are still rooted in the traditional believe system in divinities.

7 TURNER 1982: 201.

${ }^{8}$ Generally denotes the incarnation or possession of an individual by some spiritual being and not by some vague 'external forces'. According to the culture, the spirit may 'possess' or control the individual person in a number of different ways - it may reside in the head, 'ride' the individual as a horse, or a spirit might fully incarnate the person, taking full control of his or her body - and the person is 'seized' by the divinity or spirit. He or she then becomes a 'vessel' or 'temple' or the embodiment of the spirit.
} 
gods do not generally grant interviews to ethnographers, what kind of access can we have to such worlds? What does it mean to be embodied by a deity, to be-there and not-there at the same time?'

The kind of scientific enquiry to explain developments in the interest of gaining deeper understanding into this area lies in the foundations of human corporeal actions. Dance determines the nature and form of the enquiry and thus serves as evidence of spirit-possession that is supported by philosophical and religious dogmas exiting only in the debris of its corporeality in performance. Ritual is performative and so is the dance. In an unlikely situation where possession occurs without dance, the epistemological enquiries into its elements might vary in understanding its form. Nonetheless, locating spirit-possession in the Brekete cult to be concomitant with a dance provides that physical mastery into understanding the "extraordinariness" claims in the ritual practice. Therefore the key distinction between the dogma in possession dance transcendence and efficacy as "extraordinary" evidence, to a larger degree, is symbiotic with the performativity of possession manifestation within time and space.

On one hand, the idea of performance and performativity as Ann David states, 'considers everyday actions as well as rituals and artistic event as performative and seeks to analyse the "doing" of performance across a range of modalities of artistic cultural expression'. ${ }^{10}$ Ritual actions in the Brekete cult like prayers, divination, sacrifice, singing, drumming, costuming, dancing, and the conceptualization to which these acts are brought bare within a specifically assigned day places emphasis on a religious collective context to which the process in the actions become highly ritualized. In so doing the processes by which these collective actions are being performed have gone through several times of training, learning and studying and as such it continues mastered performance make up the transmission processes that lays the foundation in the epistemological evidence to which spirit-possession claim to attain. David (ibid.) in expressing an idea from Schwartz L. Susan (2004) opines that, 'studying and performing the very "embodiment of a cultural tradition" [in this case, Brekete dance] is the gaining the kinaesthetic understanding of the cosmological and ontological knowledge of the deities'.

In this vein, the relationship between the structural component of $W u$ (dance without possession) and Trowo le ewu $d u$ (dancing deities) represents the most direct form of contact with the supernatural. For example, at Dansoman, I witnessed a child of a devotee who was believed to have been afflicted by an evil spirit during her school hours taken through a healing ritual. To me she seemed physically fit but during the interplay of music and dance, spirit-mediums manifested themselves and took the child into an inner shrine, where she was bathed with herbal water, given kaolin and leaves to eat, and her body was smeared with a white kaolin chalk. Finally two spirit mediums covered the child fully with their costume; underneath it were some sort of burning plants or incense evaporating with smoke.

With the physical mastery of bringing to life the intangible, devotees of the Brekete cult instead of waiting for the deities to come to them, they rather manipulate ritual element through a performance lens to bring themselves in ritual equilibrium with the supernatural by dancing.

\footnotetext{
${ }^{9}$ Friedson 2009: 9.

${ }^{10}$ Friedson 2009: 219.
} 


\section{PERFORMING THE DANCES IN BREKETE RITUAL}

The rhetoric in social science research and the conceptualization on the terminology for dance sometimes pose problems for dance researchers to articulate the concept of dance. Although this thought on the term dance which is cast in ways characteristic of western phenomena is not new to social science literature, I would like to reiterate that this conception of dance as a homogenous activity does not allow me to use the word as such to describe the different forms of bodily movement in the ritual activity.

In light of that, there is no one single generic word which refers to these two bodily forms in motion. To do a dance without possession in the Brekete cult is $W u$, this refers 'to a collective expression of history and culture through drumming, singing, movements and gestures"11 and to say a possession dance is ongoing, is to refer to the tro or trowo (plural). Tro always refers to deities among the Anlo group of people and the Ewes as a group. In Westermann Diedrich's Ewe dictionary ${ }^{12}$, Tro among its many meanings is 'to turn', 'to return' and 'to change'.

Therefore practitioners only say Tro or Gorovodu, (another name for the deities in their material form) or Tro di amedzi (deity has embodied or mounted its medium): this reference to the deity is made depending on which deity is manifesting itself. In a more specific situation where emphasis is placed on the possession dance, then, practitioners say Trowo le ewu du (deities are dancing) again, referring specifically to the spirit-god and maintaining the word $W u$. Devotees also say Trosi or Trosiwo le wu $d u$ implying possessed medium in motion not necessarily referring to a specific deity.

I will next identify the differences between $W u$ and Trowo le ewu $d u$ by focusing on movement phrase, motifs, sequence and the features of movement variations. At present will concentrate on when the dances are done, how they are performed, who performs which dance and in relationship to what.

\section{$W U$ : DANCE WITHOUT POSSESSION}

'Union of sound and action is of importance whatever the context, there must be drumming and dancing at the funeral as at the festivals. ${ }^{13}$ With the practices of the cult activities functioning parallel with music and dance there is a union of sound from the brekete drum, awukuwo, its devotees (atikedeviwo) and other observers. 'Universal' is the term used by my informant, son of Anane Gatsi, Kpedziga Paa Willie: 'universal is something that can go anywhere, do anything ... when you play brekete right now, brekete will invite different spirits to come and see him. But when you play in another cult, Brekete ${ }^{14}$ will not be there. Brekete invites both people and spirit ... it is united and universal. It is united within itself and universal. Brekete likes crowd ... it is something

${ }^{11}$ KUwOR 2013: 19.

${ }^{12}$ Westermann 1973: 224-245.

${ }^{13}$ Nketia 1963: 174.

${ }^{14}$ Brekete with the capital letter 'B' represents the dieties Kunde and Ablewa whilst brekete (italics) represents the lead spiritual drum. 
beautiful people like to see. ${ }^{15}$ It is within this beauty, unity and universality at all ritual events that the $W u$ is performed. The universality of Brekete and the performance of $W u$ may be experienced within any physically created space: at an invitation to a funeral at a different shrine (from the devotees of other deities), at the funeral of a Brekete devotee within any cult member shrine, and at festivals and other ceremonies to commemorate the entire pantheon.

However, there is only a thin line between $W u$ and Tro di amedzi or Trowo le ewu du. This thin line is perhaps very visible to an outsider through the changes in motion of the body but less so through the audible rhythmic variation emanating from the brekete.

Devotees of the Brekete cult and the mediums do not dance for the sake of dancing. $W u$ is performed to show gratitude, commemorate, propitiate, as a sign of reverence to Kunde and Ablewa and the other deities and serves as a prelude to the possession dance. Trodi amedzi - or Trowo le ewu $d u$ - is the cognisant state of beneficence; it is the channel through which the core purpose of the supernatural is contacted and tapped for essence. The encapsulation of the transcendental within the Brekete Gati cult is well acknowledged in the values attributed to music and dance that are closely integrated with their ceremonial life.

\section{PERFORMING THE $W U$}

Performing the $W u$ is a regularity governing the manifestation of possession. In addition to the other elements of ritual behaviour, $W u$, as a dance preceding a liminal state, becomes a kinetic symbolic channel of adaptation to the Brekete pantheon. The idea of adaptation is to 'link a social system and its environment, specifically extracting goods and services from the environment for the society. ${ }^{16}$ This idea is not far from the conceptualization of certain human movement skills that are practiced as dance in Ghana. Dances such as Kpanlogo, Kundum, Adowa and so on in their movements were developed and motivated through their natural habitat in fishing, planting \& harvesting, and hunting, respectively. Therefore most dance patterns in Ghana are inherently laden in psychobiological and social experience and environmental philosophies. However, these dances in their broader practice do not disappear or survive through adaptation.

'Dance continues to facilitate adaptation to the supernatural environment. ${ }^{\text {'17 }}$ And if efficacy is the end product of the ritual, then the $W u$ dance as an adaptation to the supernatural evokes or perhaps I may put it 'extracts' the pantheon of deities believed to be embodied in their natural habitat. How is this manipulation manifested? Foremost, through the processes of the ritual structure during Sallah, ${ }^{18}$ observing the (Ramadan, Eid Al-Fitr

15 Interview, July 2013.

${ }^{16}$ Annual Meeting of the Southern Anthropological Society, Columbia, Missouri, February 24-26, 1972.

${ }^{17}$ Hanna 1973: 8-9.

${ }^{18}$ An Arabic word for prayer. In the context of Brekete it incorporates drumming, singing, dancing, incantations, presenting of items and prayer to the deities and finally possibility of possession. Friday is the chosen day for sallah because the inherited gods are of Muslim origin and as such they still have their Muslim attributes of observing the everyday Muslim prayers on Friday. 
and Eid Al-Adha) Islamic (Hijrah) calendric holidays, and some ceremonial occasions. $W u$ comes after all other rituals and before possession. These ritual behaviours begin with rhythmic call from the Awuku (brekete lead drummer) and the Awukuwo (drummers) to all the Atikedeviwo (devotees; including the clapper players).

Next are prayers, singing and incantations session led by Kpegdziga Paa Willie. Drumming stops at some point within this session. Then, depending on the ceremony (Sallah or annual festival), Kpegdziga may allow one sentry to collect ritual items from the devotees to propitiate the deities first or allow the drummers to continue making music before the Sentry collects the ritual items.

During the next phase, Kpegdziga Paa Willie and all the women devotees excluding the drummers present the ritual items to the Gorovodu (material form of the deities) on their respective altars in the shrine through $A f a$ divination. During this time there is no singing and music making. The performance of the $W u$ by all devotees comes next leading to Tro di amedzi (possession), which continues for a while and eventually brings the ritual to an end.

To conclude on some of the processes regulating the ritual activity and the structural function in performing the $W u$, the aim of which is to develop the differences between both dances, it is expedient to understand that all the other ritual elements are equally preparations for gaining physical access to the supernatural. But if I may assume heuristically, these ritual preparations for efficacy to an extent perhaps can be likened to heat (thermal) conduction and thermal radiation in physics. Both are a possible combination in the transfer or flow of heat.

This hermeneutics, however problematic it may seem or sound, is to open other tentacles and further raise discourse into the notion postulated. But within the purview of anthropology, I am not suggestive that deities are either microscopic particles (molecules, electrons, atoms, phonons, etc.) or radiative substances (objects) or their ontological and cosmological processes of scientific manifestation, for this phenomenon is an area science is yet to control. But, the idea being put forward here is that there is absorption and emission of a supernatural force in possession as it is in thermal radiation, and likewise, the onset of possession (absorption) in Brekete is always marked with great outburst (emission) of force or energy from spirit-medium.

\section{WU MOVEMENT: PATTERN OF STRUCTURE, GROUPING, STYLE AND MUSIC}

In my unpublished research I analysed the $W u$ and I stated that 'The dancing has a pre-defined order and devotees never dance alone; they either dance together in two, three and four. And, depending on the direction; either towards the Bishop, drummers and other devotees where the dancers are heading towards, on reaching that point, they either take a bow or prostrate. ${ }^{\prime 19,20}$ The introductory sentence as to the dance having a pre-defined order

${ }^{19}$ (1) Kneel on both legs, (2) touch the floor with elbows, chin and forehead, (3) stand up, return to sit by dancing. Or (1) bend down, (2) touch the floor with either hand or both, and (3) touch forehead and the chest.

20 OKYERE 2014: 16. 
shall be the premise of the following discussion. There are two choreographic forms to this dance: a circular pattern in an anti-clockwise direction, creating a centre of focus in the middle, and a linear pattern, which creates the relationship between the Bishop, drummers and other devotees. The anti-clockwise circular pattern only creates a relationship between the dancing devotees within the circle. Performing the choreography of $W u$ is quite simple. What I experienced and observed as a participant during ritual moments was that devotees rise to dance as the music sets the mood. At first all women devotees play the clapper, men play the other musical instruments with the Bishop specifically and most often playing the dondoo. Any of the women devotees may initiate the dance in rhythm to the bell phrase and the rest will follow.

\section{WU FOOTWORK}

Starting with the right or left foot being active, the foot work order in four counts will be: (1) hold body weight on either leg, and gesture the other leg on a forward diagonal, (2) step on gestured foot to hold body weight momentarily, (3) holding weight on either leg, gesture the other leg, (4) step on gestured feet to balance the weight momentarily. This two-step that is repeated in sagittal symmetry moves the dancers forward in the anti-clockwise circle and also in the linear pattern of dancing in two, three and four groupings. Hence, count one and three holds the body weight on one leg and dancers do a full leg gesture, while count two and four balance the weight on both feet to end the gesture with a step and preparation to transfer the body weight. This is the standard footwork in both forms but the footwork in the anti-clockwise choreography may sometimes change as this is not strictly choreographed, which gives much more flexibility for creativity and enables dancers to express their movement playfully with the bell phrase. It was through the openness of the anti-clockwise form that I experimented with the footwork and dancing the $W u$.

A devotee in the circle may choose to step four counts on one foot in sagittal symmetrical repetition as she moves forward but again the tempo never changes from allegro. Others may also (1) step on the right foot, (2) hold weight on right foot and prepare to transfer, (3) step on the left foot, (4) hold weight on left foot and prepare to transfer.

There is a philosophical underpinning in dancing anti-clockwise in the sociocultural fabric in Ghana. Thus, dancing towards the anti-clockwise direction symbolizes dancing towards life. In the oral philosophy, circle means life, wholeness and community; oral sources therefore are largely the foundation of most dance existence. As Georgiana Gore in Traditional dances in West Africa states explicitly, '...oral sources constitute a privileged means of access to constructing dance histories, especially as the music, in particular drumming and song which accompany the dance usually refer in some way to the meaning, history or context of the dance'. ${ }^{21}$

${ }^{21}$ Gore 1994: 79. 


\section{ARM STYLE}

In the anti-clockwise dance form, the arm just like the foot may move creatively depending on the footwork. Devotees will mostly keep their arms close to their body for a moment and swing both arms to the side in a pendulum motion manner. Another style is keeping the lower arm raised to waist level, dropping it for a while and then lifting it again. However, in the well-defined sequence of the linear choreography, the arms move in relation to the first active foot also maintaining sagittal symmetry. Therefore, on the same bell phrase and flow, the counts will be (1) preparation to move lower arm towards the chest and moving it towards the chest, (2) the lower arm flexes toward the chest, (3) the lower arm is held for one count and returns to place, (4) the lower arm arrives in place and prepares to repeat the cycle.

Hence, counts one and four begin arm movement and end it while counts two and three hold the lower arm through to the upbeat and return.

\section{MUSIC}

Ewe music is homogenously polyrhythmic and so is the music in Brekete, which is symbiotic with these polyrhythmic phrases. The musical ensemble in Brekete is formed of the 'traditional Ewe music ensemble', ${ }^{22}$ however, what makes the Brekete musical instruments different is the addition of the 'brekete, Dondoo" ${ }^{23}$ (also known as the talking drum or hourglass drum), bamboo clappers and apentemma ${ }^{24}$ combining with Sogo, Kroboto, Kangan, Atoke and Axatse. The dondoo, axatse and apentemma are used on occasional basis.

Accordingly, sounds emanating from all these instruments coupled with singing unify into a kaleidoscopic phrase, engaging all the senses of the devotees in varied bodily actions. The rhythmical structure, therefore, is multidimensional in meter. The flow of time in both dances is shaped by four ternary beats (dotted quarter note) within one bell phrase. David Locke (2009) refers to these ternary beats as ternary-quadruple ${ }^{25}$. Also the flow in the bell phrase is in between fast and lively, in musical terms allegro and vivace. Count one is the first beat (downbeat), count two fills in between counts one and three, count three is the midpoint (upbeat) and the cycle is repeated on count four.

${ }^{22}$ Atimewu - Head of all the drums; tallest and largest, Sogo - master support Drum, Kroboto/Kidi master support drum; slightly bigger than Kangan, Kangan - smallest support drum, Gakogui/Gakpevi - iron double bell/forged iron carrying a child, Atoke - banana bell, Axatse - gourd hollowed out \& woven around with beads to rebound rattling sound.

${ }^{23}$ Adapted drums from the Hausa/Muslim group of Northern Ghana (Dagarti). Dagarti land is believed to be where the Brekete deities came from.

${ }^{24}$ In addition to 'petia, operenten and apentemma' belong to the shrine drums of the Ashanti group of people (NKetia 1957: 103).

25 'Rather than using the terminology of Western music - compound time or 12/8 time signature - I will designate this temporal structure as ternary-quadruple, i.e., beats hold three equal units, with four beats within one occurrence of the bell phrase. The temporal units within beats are termed fast pulses or time points 


\section{TRJDI AMEDZI: POSSESSION}

Belief as in the ontological nature within the Brekete cult holds that deities specifically chose individuals among the devotees to regulate and be responsible for certain roles in the ritual functioning and cult organization. But such roles as mediums are designated by the deities who, thus, exercise their supernatural mastery through the medium's body may be chosen within the cult from amongst, practicing members or they non-members having an association with the cult. These mediums through ritual rites maintain an immediate relationship with the Brekete pantheon until the demise of the medium.

It is worth mentioning that there is a close relationship between the individual medium (secular) and their deities. This relationship, moreover, is either established through biological ties or through the individual's personal or family affiliations to the deities and the cult organization.

And in order for mediums to get possessed and for the deities to manifest themselves in dancing, this relationship has to be established beforehand. However, not every devotee can be a medium and to experience spirit possession.

\section{PERFORMING TRJ WO LE EWU DU: POSSESSION DANCE}

The processes in the manifestation of the celestial pantheon within the Brekete cult maybe likened to the process in thermal radiation. The possession dance as a successor of the $W u$ dance, perhaps, is thought to absorb the internal flow of energy coupled with the heightened musical rhythms demonstrating the physical mastery of the deities.

Hence, before the dancing begins in the pre-liminal stage of possession the medium experiences the absorption of the deities' supernatural force. This is always marked with a great emission of energy from the medium's bodily action. Therefore, the threshold of possession catapults the medium from a sitting posture in a violent burst of energy. The medium leaps up, often with a high-pitched shriek, grasping for support from sentries. The eyes are tightly closed, upper torso and arm closely held together and stiffened, gross tremors seize him or her, and total facial appearance conveys intense consternation. Because mediums hold onto the musical clappers before they stiffen, sentries attending to them blow air onto their hands for them to release the clappers and throw broken kaolin chalk on their body.

The mediums maintain this state of seizure for a while as they respond to the symbolic connection of these treatments. They abruptly engage in series of whirls that are characterized by great force and in that momentum, stop suddenly. The pause is followed by a bend of the upper torso going below the transverse plane of the body and with both arms of the medium wrapped around the shoulder and holding the joint tightly. The emission of actions from the medium create for her a betwixt and between feeling of pre-liminal and liminal state of possession. The medium releases the hands from the shoulder joint and urgently requests for water by stretching the arms forward and alternately rubbing the hands against each other and again on the head. Without delay, the sentries grab a buta filled with water to pour out onto the hands of the spirit-medium as he/she washes the hands, legs and feet, and the head while maintaining the bent position. 
However, possession almost never overtakes a medium while performing the $W u$ dance. Rather, it is most often while the mediums are singing and playing the clappers in a seated position that this happens. Furthermore, it is during this state of liminality that most of the embodied pantheon begin to dance and are referred to as 'trowo le ewu $d u$ '.

\section{TRכ WO LE EWU DU MOVEMENT: PATTERN OF STRUCTURE, GROUPING, STYLE AND MUSIC}

Movement structures within the possession dance employ improvisation in the use of space. A dance researcher can never predict which direction a deity might be heading towards. In contrast to performing the $W u$, movements of deities in space can be mapped out as forward, backward, diagonal, sideways locomotion and whirls. But the choreographic patterns in body dynamics never changes and are always repetitive in all ritual functions.

Deities will mostly take turns to dance to a specific music relating to their own characteristics or to a general musical accompaniment from the brekete. They may occasionally dance in formations of four or five but largely, when most deities dance in groups, they dance individually in relation to the group.

Also, the bell phrasing as I elucidated earlier keeps to the flow of four ternary beats but the tempo is characterized in lively or vivace style and the rhythmical structure to the dance is shaped in accentuation and phrasing.

\section{TRJWO LE EWU DU: FOOTWORK OF THE DEITY SAKRA BODE}

Sakra has a fast foot shuffle movement backwards and forward and starts with the right or left foot being active. The footwork order in four counts to a lively tempo is: (1) a gesture with a high stride on the left leg and hold body weight on the ball of the right foot, (2) a stamp on the left foot, keeping weight on the left leg and a gesture with the right leg backward, (3)a stride on the right foot beside the left foot to share body weight briskly and a quick shuffle with the left foot backward and right foot forward, (4) a gesture with a high stride on the right leg holding body weight on the ball of the left foot. Again, the execution of the footwork is in sagittal symmetry. The count one, two and four alternates as body weight shifts on each leg. But count three shares the body weight briskly within that tempo flow and count four is still the turnaround to start the repetition. Nevertheless, this extraction of movement analysis is without the detailed motif breakdown in the whirls and feet shuffle.

\section{ARM STYLE}

The movements of the arms without detailing the relation to the bell count because of its complexities but which is symbiotic to the four ternary beats function in a contra- 
kinetic ${ }^{26}$ manner in relation to the footwork. The arm alternates most often with the left crossing over the right, outstretched and momentarily folding around the shoulder. The hand opens and closes along with the arm action. The physical imagery or feelings being created in these actions are as if grabbing/picking and releasing something, collecting and dispersing/throwing, pulling/evoking from underneath.

\section{PHILOSOPHY OF REPETITIVE MOTIF CHARACTERISED BY INTENSE ENERGY, RHYTHMIC TEMPO AND MUSICALITY FROM THE BREKETE DRUM}

In the theory of music studies and neuropsychological analysis there is the potential that music can ignite frequencies in the brain thereby causing a state of trance or possession. Instead of a neuropsychological analysis, in this enquiry I will demonstrate how music is used to play a role in achieving the performance of possession through a corporeal and music relationship. And further on how embodying the knowledge of the transcendental perhaps is attained through the performance lens of rhythmical multidimensionality, accentuation and phrasing.

The rhythmical structure in the Brekete cult is highly regulated during ritual activities. The brekete drum on the other hand is believed to be a spirit and thus has the capability to conjure transcendental power. An example of an anecdote by Kpedziga Paa Willie shed light on this in an interview: 'drumming, singing brings the spirit ... so when we're drumming all the time they will come'. Nketia, an ethnomusicologist also observed this notion and contends that 'state of ecstasy or of possession can be quickly induced and sustained by means of special music closely correlated with specific forms of bodily action. It is believed also that the gods are sensitive to this music.... The player of the brekete is also believed to have a spiritual calling and ability to manipulate interchangeably the rhythms at some point.

The concept of rhythmical multidimensionality involves cross-rhythm and polymeter that occurs simultaneously to form musical rhythm into proportions. David Locke (2011) refers to this as 'simultaneous multidimensionality (metric matrix)'. He articulates this further that cross-rhythm indicates that the musician stays grounded in one time-feel perspective, equivalent to time signature in Western music, while polymeter means that the metric background shifts.

The time feel in the Brekete ensemble as I earlier discussed is in four (per the $4 \times 3=$ 12 framework of beats and pulses which is equivalent to 12/8 time signature). In relation to the ensemble, the bell phrasing, the bamboo clappers, Kroboto, Kangan and Axatse are the instruments grounded in this time feel, yet the sound emanating from each instrument and how they are played is not synonymous. The brekete, sogo and dondo, which are predominantly used, are the instruments which, although maintaining the time feel, create that pattern of shift.

26 '...idea of contrakinesis as an immediate, successive movement opposition, which means movement pairs where a movement is followed right on the next rhythmical unit by an opposite one. Contrakinesis is primarily a principle of motive creation...' (FÜGEDI 2006: 43) 
After critically analysing and comparing the movement motifs of $W u$ to the movement motifs of trowo le ewu du, my analytical argument is that there is a change in tempo from fast in the $W u$ performance that causes a simultaneous presence of multiple time feel in the trowo le ewu du to vivace to create a distinctive type of bodily accentuation, thereby portraying possession.

David Locke postulates that

A unison moment occurs when beats in different streams occur simultaneously: a special musical feeling arises when separate timing flows meet. Beats also are offset from each other in predictable rhythmic relation: each offset moment has a distinctive musical quality or rhythmic feeling tone. ${ }^{27}$

The arousal of musical feeling and tone produced by the drummers creates the communality of the activity and thereof put the dancers in a state of effervescence to essentialize and accentuate the movement motifs on the meeting point of the time flow. In the vein of this argument, movement accentuation relating to the leg, foot, and arm occur on beat one and two on the bell time feel.

Hence, the performing deity identified as Sakra Bode on beat (1) gestures with a high stride on the left leg and holds body weight on the ball of the right foot, beat (2) stamps on the left foot, keeping weight on the left leg and gesture the right leg backward. The left foot kicks the air with such a force in the accentuation of those beats and essentializes that movement with a hard stamp on the ground, propelling a rapid shuffle to repeat the movement on the other leg. The arms thereby stretch out towards the ground rapidly and quickly jerk upwards on beat one. The feeling is as if grabbing and pulling something and then releasing it back with a force. Throughout the accentuation and essentializing moments, the body weight alternates between the right and left leg, respectively, on beats one and two, and momentarily on both feet on beat three. On the contrary, the same performer doing the dance without possession on the same time feel, on beat (1) gestures low on the left foot and puts weight on the right leg, (2) steps on the left foot, (3) steps on the right foot beside the left foot and (4) holds both feet and repeat movement on the other foot. The arm flexes and extends within the four ternary beats.

\section{CONCLUSION}

In a nut-shell, philosophical assumptions, questions and findings will never suffice to satisfy our curiosity to the phenomenon of religious possession dance. Likewise, anecdotes of religious experiences will also not be enough to support this area of claim because of their narrative approach and rational argument. Although dance and the corporeal human action is not an end to this epistemological enquiry, the mastery of its nature offers the potential to establish an empirical premise in this field. Through the structured movements of dance and its corresponding components in relation to other contributing elements, researchers are aided with this ephemeral yet empirical data to deconstruct the tenets of possession dance phenomena.

${ }^{27}$ Locke 2009. 
This research on the Brekete I hope has captured or attempted to capture in a different purview the varying ideas and knowledge about religious spirit possession rituals. Through the examples given in the religious experience anecdotes, ontological and cosmological belief, and the movement analysis that was paralleled with rhythmical analysis on the $W u$ and Trowo le ewu $d u$. This research has uncovered that the state of possession is characterized by changes in the corporeality of the $W u$ in relation to the Trowo le ewu $d u$. Such corporeal actions like the sudden outburst shriek and catapulting from the seat do not only identify these changes but rather the $W u$ performers' feet doing a slow shuffle seems to detach the physical self of the medium from his/her immediate relations and when the medium is believed to have been transposed into a deity his/her amplitude of movement is fast with large strides. While performing the $W u$ on beat (1) the left foot gestures low and puts weight on the right leg and on beat (2) the gestured left foot steps on the ground. In the same time feel but with a different tempo in performing Trowo le ewu $d u$, on beat (1) the left leg essentializes a gesture with a high stride and holds the body weight on the ball of the right foot, on beat (2) left foot accentuates a stamp, keeping weight on the left leg and gestures on the right leg backward.

Concluding on movement dynamics on both performances, travelling in space is done symmetrically with steps, hip shifts, foot kicks and alternating arms, free end of the arms towards the chest and back. In totality, the general feeling in the projection of quality in performing the $W u$ is slowness of energy released in space. Energy in this context is being related to athleticism and the physical appearance of the performance. The expressive nature of the $W u$ dancers is in a relaxed mode to accomplish movement. However, the flow in the Trowo le ewu du performance is more expanded in movement due to the intense energy and rhythmic tempo showing fast foot shuffle, large strides, lunges, jumps and whirls. The quality of the movements projected is vigorous, vibratory and force; the arms wrap around the shoulder and are quickly thrown about, the hands beat the body with a clinched fist and fast foot kicks. All these qualities are executed in musical multidimensionality, accentuation and phrasing from the brekete drum.

The study finally has highlighted how through dance the cultural phenomenon of a people could be learnt and perhaps the fundamental dogma appreciated in a coexistent manner. In summary, Hannah assumes that, 'Dance is culturally patterned and meaningful ... it reflects other cultural manifestations and is a vehicle through which culture is learned'. ${ }^{28}$ In an attempt to articulate the different modalities at which possession ritual and its efficacy are performed within one socio-cultural context I hope the above enumerations, if not entirely, but at least the breath and length of the performative actions in the ritual performance have captured the idea which the discussion was intended to achieve.

\section{LITERATURE}

Bourguignon, Erika

1976: Possession. Prospect Hills, IL: Waveland Press.

DAVID, Ann

2011: Gendered Dynamics of the Divine: Trace and Possession Practices in Diaspora Hindu Sites in East London. In: Dawson, Andrew (ed.), Summoning the Spirit: Possession and Invocation in Contemporary Religion. London: I.B. Tauris \& CO LTD, 74-90.

${ }^{28}$ HANNA 1987: 30-31. 
ERIKSEN, Thomas H.

2001: Small Place, Large Issues. An Introduction to Social and Cultural Anthropology. Second Edition. London: Pluto Press.

Friedson, Steven M.

2009: Remains of Ritual: Northern Gods in a Southern Land. London: The University of London Press.

Fiawoo, Dziigbodi Kodzo.

1968: From Cult to 'Church': A Study of Some Aspects of Religious Change in Ghana. Ghana Journal of Sociology 4(2), 72-87.

FÜGEDI, János

2012: Motivic Mircostructures and Movement Concepts of Expression in Traditional Dances. From Field to Text \& Dance and Space. Proceedings for the $24^{\text {th }}$ Symposium of the ICTM Study Group on Ethnochoreology. Cluj-Napoca 2012.

GeErTz, Clifford

1966: Religion as a Cultural System. In: GeERTz, Clifford, The Interpretation of Cultures: Selected Essays. London: Fontana Press, 87-125.

Gellner, N. David

1999: Religion, Politics, and Ritual. Remarks on Geertz and Bloch. Social Anthropology 7(2), 135-153.

Gore, Georgiana

1994: Traditional Dance in West Africa. In: Adshead-Lansdalean, Janet - Layson, June (eds.), Dance History. An Introduction. London: Routledge, 59-80.

Grau, Andrée

1987: Presentation on a Two Week Intensive Program in Norway. In: Hanna, Judith L., To Dance is Human. A Theory of Nonverbal Communication. Chicago: The University of Chicago Press.

HanNA, Judith Lynne

1973: African Dance: The Continuity of Change. Yearbook of the International Folk Music Council 5, $165-174$. Kuwor, Sylvanus K.

2013: Transmission of Anlo-Ewe Dances in Ghana and in Britain: Investigating, Reconstructing and Disseminating Knowledge Embodied in the Music and Dance Traditions of Anlo-Ewe People in Ghana. (Doctoral dissertation, Roehampton University).

KWAKwa, Patience

1972: Dance and Drama of the Gods: Case Study of Masters Thesis. African Studies Department, University of Ghana.

LOCKe, David

2009: Simultaneous Multidimensionality in African Music: Musical Cubism. African Music 8(3), 8-37.

Nketia, J. H. Kwabena

1957: Possession Dances in African Societies. Journal of the International Folk Music Council 9, 4-9.

1963: African Music in Ghana. Evanston: Northwestern University Press.

OKYERE, Senyo

2014: The Role of Dance and What it Teaches about the Transcendence in Possession and Efficacy among the Brekete Gatsi Cult of Ghana. (MA dissertation, Norwegian University of Science and Technology, Roehampton University)

Parrinder, E. Geoffrey

1960: The Religious Situation in West Africa. African Affairs 59(234), 38-42.

SCHECHNER, Richard

1994: Ritual and Performance. In: Ingold, Tim (ed.), Companion Encyclopedia of Anthropology: Humanity, Culture and Social Life. London: Routledge, 613-647.

TuRner, Victor

1982: Dramatic Ritual/Ritual Drama: Performative and Reflexive Anthropology. In: Turner, Victor, From Ritual to Theatre. New York: PAJ Publications, 89-101.

Westermann, Diedrich

1973 [1928]: Evefiala. Ewe-English Dictionary. Nendeln: Kraus Thompson. 